\title{
Vicente Cueto
}

No todos pueden darse el lujo de tomar un baño de multitud; gozar de la turba es un arte.

BAudelaire, "Las turbas"

\section{§ 1. Introducción}

Después de siete años de exilio en diferentes ciudades europeas, Walter Benjamin muere en 1940 intentando cruzar la frontera entre Francia y España. Había atravesado los Pirineos esperando poder luego viajar a Estados Unidos. Escapaba de los nazis. Deja incompleto un proyecto que había emprendido casi dos décadas atrás: "la construcción histórico filosófica del siglo XIX como tiempo en que nace la sociedad industrial” '. Sus ensayos sobre Baudelaire tienen este propósito. La figura y obra del poeta sirven como punto de partida para presentar y problematizar la modernidad.

Este trabajo se centrará en "Sobre algunos temas en Baudelaire"2, texto que Benjamin publicó en 1939. Se trata de la corrección de un escrito previo, "El

\footnotetext{
I Aguirre, Jesús, “Walter Benjamin: Fantasmagoría y objetividad”, en: Aguirre, Jesús (ed.), Benjamin, Walter. Poesía y capitalismo. Iluminaciones II, Madrid: Taurus, 1993. p.I6.

2 Benjamin, Walter, "Sobre algunos temas en Baudelaire", en: Aguirre, Jesús (ed.), Benjamin, Walter. Poesía y capitalismo. Iluminaciones II, Madrid: Taurus, 1993.
} 
París del Segundo Imperio en Baudelaire", que Theodor Adorno había criticado severamente. Adorno le había dirigido una carta desde Nueva York, reclamando el estilo de Benjamin de enumerar temas sin desarrollarlos, con la esperanza supersticiosa de que algo ocurra a partir de esta reunión de ideas ${ }^{3}$. Consideraba que hacía falta mediar el análisis de Baudelaire y del Segundo Imperio a través de la teoría marxista. Sibien es cierto que encontramos reflexiones sobre situaciones muy concretas que no llegan a articularse en una teoría (muchas veces, es difícil encontrar un hilo conductor), esta era precisamente la intención de Benjamin.

En El origen del drama barroco alemán, Benjamin parece describir su propio estilo: "Es práctica común en la literatura barroca apilar fragmentos incesantemente, sin un propósito determinado; $y$, con la constante esperanza de que ocurra un milagro, llevar la repetición de estereotipos a un proceso de intensificación”4. Las reflexiones sobre París y Baudelaire se suceden rápidamente, parece que el autor no se detiene en ninguna en particular, sino que las va juntando, una detrás de otra, para esbozar una imagen de la modernidad.

La relación entre Adorno y Benjamin se remonta a 1925, año en el que se conocieron. De acuerdo a Wiggershaus, empezó una relación provechosa para ambos. Adorno lo convirtió en colaborador de la revista Zeitschrift für Sozialforschung y posteriormente en miembro de la Escuela de Frankfurt ${ }^{5}$. Por otro lado, Benjamin tuvo una profunda influencia en el pensamiento de Adorno 6 . Volviendo a la crítica de Adorno a "El París del Segundo Imperio", el filósofo reconocerá más tarde que "era intención de Benjamin renunciar a toda interpretación manifiesta y dejar que las significaciones saliesen a la luz por medio de un montaje chocante del material"7.

"Sobre algunos temas en Baudelaire", como ya dijimos, es una reformulación del primer texto: las reflexiones son las mismas, pero parecen haberse

3 Cf. Kelman, David. "The Inactuality of Aura. Figural Relations in Walter Benjamin's 'On Some Motifs in Baudelaire”", en: Petersson, Dagy Erik Steinskog (eds.), Actualities of Aura. Twelve Studies of Walter Benjamin, Göteborg: NSU Press, 2005, pp.125-I26.

4 Citado por David Kelman en: ibid., p.I26. La traducción es mía.

5 Wiggerhauss, Rolf, La Escuela de Fráncfort, México D.F.: Fondo de Cultura Económica, 2010, p.III.

6 Cf. ibid., p. 97.

1047 Citado por Jesús Aguirre en: op. cit., p. 18. 
condensado. No recurre al dogma marxista como exigía Adorno, sino más bien al psicoanálisis (Freud) y a la filosofía de la conciencia (Bergson y Proust). La idea central de este ensayo es que estos referentes teóricos le permiten a Benjamin presentar al poeta como conciencia de la multitud. El habitante de la gran urbe recibe estímulos que no puede procesar. Al no poder captar lo que él mismo experimenta, todo un ámbito de su vida le resulta ajeno. La masa es incapaz de tomar conciencia de sí misma. El poeta, en cambio, recorre la multitud recogiendo lo que a ella se le escapa. Sin embargo, no cumple una función catárquica ni redentora. La referencia del poeta al inconsciente colectivo no es reconciliadora, sino crítica: señala su condición alienada.

\section{§ 2. El contexto}

Las dos entregas sobre Baudelaire a las que nos hemos referido tienen como escenario el París del siglo XIX. En 1852, Napoleón III se convierte en el emperador de Francia y emprende una serie de medidas para modernizar la ciudad. Junto con el arquitecto Haussman dan inicio a una reestructuración urbanística. Hasta ese momento, París había permanecido como una ciudad medieval, con calles estrechas y problemas de salubridad. Haussman intenta reorganizar las viviendas, expropiando muchas, para luego destruirlas. La intención principal era crear más espacio para poder ensanchar las calles. La ciudad se moderniza, aparecen las grandes avenidas y los paseos, proliferan los cafés y las tiendas. "Se abría una vasta red de bulevares en el corazón de la vieja ciudad medieval. Napoleón y Haussman imaginaban las nuevas calles como las arterias de un nuevo sistema circulatorio urbano"8. Ahora no sólo es más fácil desplazarse por la ciudad, sino que grandes masas pueden atravesarla.

\section{§ 3. Los lectores}

Cuando Las flores del mal se publicó, los lectores habían perdido el interés por la poesía lírica. Solo tiempo después, el poemario se convirtió en una

8 Berman, Marshall, Todo lo sólido se desvanece en el aire: la experiencia de la modernidad, México, D.F.: Siglo Veintiuno, 2006. p. 149. 
obra importante y difundida. Este desfase le servirá a Benjamin como punto de partida: si la poesía lírica ya no puede hacer contacto con la experiencia de los lectores, entonces esta última debe haberse modificado en su estructura. ¿Cómo entender la experiencia de los lectores? Baudelaire, en el poema introductorio de Las flores del mal, caracteriza a los lectores de la siguiente manera: "con su fuerza de voluntad y su capacidad de concentración no se llega muy lejos; dan preferencia a los goces sensuales; y están familiarizados con el spleen que acaba con el interés y la receptividad". Tienen la voluntad "vaporizada" y son movidos por hilos externos. No parecen darse cuenta del proceso de degradación en el que se encuentran.

Cada día hacia el infierno descendemos un paso,

Sin horror a través de las tinieblas que hieden.

¿Quiénes son estos lectores que no pueden ser conscientes de su propia experiencia? Benjamin los identifica con la multitud que habita en las grandes ciudades. En el siglo XIX, la lectura se había extendido a amplias capas de la sociedad. En este proceso, la multitud de gente empieza a exigir verse retratada en la literatura que consume. "Proporcionaba encargos, quería encontrarse, como los donantes en los cuadros de la Edad Media, en la novela contemporánea”|0. Así, al mismo tiempo que la multitud de personas se convierte en multitud de lectores, la multitud de lectores se vuelve multitud de clientes. En "El París del Segundo Imperio en Baudelaire” Benjamin examina este proceso, donde la prensa cumplió un rol determinante, con más detenimiento".

La información de los periódicos empezó a ser acompañada de cuentos y novelas por entregas que tematizaban la ciudad y la multitud. Sin embargo, la literatura se incorpora a la prensa bajo las reglas y la lógica de esta última. "Una casa puede ser muy hermosa, pero sobre todo, y antes de que nos detengamos en su belleza, tiene tantos metros de alta y tantos metros de larga. Igual pasa con la literatura, que presenta una sustancia inestimable: es,

Benjamin, op. cit., p. 123.

10 Ibid., p. 135. 
sobre todo, líneas llenas; y el arquitecto literario, al que no solo su nombre promete ganancia, tiene que vender a cada precio" 12 . Aparece un nuevo género literario: las fisiologías. Estas consisten en retratos de los habitantes de la ciudad y buscan dar una imagen inocente y alegre; sosegar la conciencia de los lectores, satisfacer las necesidades del consumidor. Por ejemplo, la imagen del obrero que se alegra solamente cuando escucha el silbido de la fábrica le permite al empresario descansar tranquilo' ${ }^{13}$. La literatura se dirige al mercado y termina siendo absorbida por este. Por otro lado, la información del periódico se caracteriza por su "curiosidad, brevedad, fácil comprensión y sobre todo desconexión de las noticias entre sí”|4. El lector no asimila las noticias como propias a su experiencia vital. Más aun, pierde la capacidad de ser afectado por los hechos que lo rodean: la función de las noticias consiste en "impermeabilizar los acontecimientos frente al ámbito en que pudiera hallarse la experiencia del lector"'5.

\section{§ 4. La conciencia}

Bergson y Proust le sirven a Benjamin para resaltar cómo la prensa dificulta el conocimiento que los lectores pueden adquirir de sí mismos. Bergson señala que el hombre solo puede experimentarse a sí mismo como duración y como parte de una tradición. Las noticias de los periódicos no pertenecen a ninguna tradición: se guían por la necesidad de lo nuevo y ofrecen una noción de tiempo discontinuo. Proust, en En busca del tiempo perdido señala que traer el pasado al presente no depende de nuestra voluntad. "Es cosa del azar que cada uno cobre una imagen de sí mismo, que pueda adueñarse de su experiencia"|6. Para Benjamin, esto no es así: sólo cuando los estímulos exteriores no pueden ser incorporados a la experiencia, la interioridad se vuelve ajena a nuestro control. Las reflexiones de estos autores giran en torno al tiempo, al recuerdo, la memoria y la experiencia humana.

${ }^{12}$ Cf. ibid., p. 46.

${ }^{13}$ Cf. ibid., p. 53.

14 Ibid., p. 127

15 lbid.

16 Ibid., p. 126. 
Con Freud, Benjamin puede desarrollar una idea que estaba implícita hasta ahora: la conciencia y la inconciencia en la poesía y la multitud. Para el psicoanálisis, todas las percepciones y vivencias de las que no somos conscientes, pero que sin embargo tenemos, se sedimentan en la memoria y pueden tener una repercusión traumática (el shock). Cuando percibimos, si lo hacemos conscientemente, la percepción se agota en ese punto: no es retenida, no penetra en el sujeto. Así, la conciencia es entendida como una defensa frente a estímulos externos que podrían resultar desestabilizadores. El recuerdo y el sueño pueden aliviar el shock, en la medida en que traen a la conciencia los estímulos desestabilizadores y los anulan.

Benjamin señala que la poesía se fundamenta en el shock y en la capacidad de actualizar aquello que permanece en nosotros como potencia destructora. La conciencia, en cambio, "esterilizará [el] incidente para toda experiencia poética"'7. Cuando Baudelaire retrata la producción poética, la compara con una lucha. El poeta pelea contra sí mismo: "inclinado sobre su mesa, penetrando una hoja de papel con la misma mirada que hace un momento dedicaba a las cosas, esgrimiendo su lápiz, su pluma, su pincel, escurriendo la pluma en su camisa, presuroso, violento, activo, como si temiese que las imágenes se le escapasen, peleador, aunque solitario y recibiendo él mismo sus golpes"18. Para Benjamin, esta lucha no se da sólo dentro del poeta y consigo mismo. El poeta retiene en su memoria las experiencias que la colectividad no ha podido procesar y las enfrenta en su poesía. "Baudelaire hizo asunto propio parar con su persona espiritual y física los shocks, cualquiera que fuese su procedencia"' ${ }^{9}$. Benjamin describe a Baudelaire como una conciencia de todos los shocks de su época.

\section{§ 5. La multitud}

La multitud no sólo es multitud de lectores y la prensa no es la principal causa de su inconciencia. La vida en París aparece en Baudelaire como la vida en la masa: la multitud es la ciudad y viceversa. La dinámica de la urbe hace que

17 Ibid., p. I3I.

18 Ibid., p. 133.

19 Ibid. 
todo aquel que se encuentre en ella, se diluya en la multitud. Poe describe cómo en la multitud y bajo la luz de gas del alumbrado público, se igualan las clases sociales: todos tienen los mismos rasgos decadentes para el espectador. Los transeúntes se mueven en la masa mirando solamente para identificar las señales de tránsito. Todos sus movimientos se dirigen a evitar obstáculos. La forma en que aprenden a relacionarse busca evitar el contacto y asegurar la circulación. "El habitante de los grandes centros urbanos cae de nuevo en el estado salvaje, quiero decir en el aislamiento" ${ }^{20}$. Parafraseando a Marx, en el trato con la multitud aprenden los peatones a coordinar su propio movimiento como el de un autómata. Sumergido en una dinámica enajenante, el peatón no puede procesar los estímulos que se le presentan. Su experiencia se le escapa. En Crítica del agravio moral, Axel Honneth sostiene que la critica social procede identificando patologías sociales ${ }^{21}$. Estos autómatas son indicativos de individuos disfuncionales.

Sin embargo, el poeta encuentra los insumos para su trabajo en la masa. En el poema "A una pasante", una aparición en medio de la multitud seduce al poeta. La mujer que aparece sólo puede resaltar en la medida en que es única dentro de la masa. La multitud la acerca al poeta y se la arrebata en un mismo movimiento. Aparece la idea del poeta rescatando el instante dentro del rápido discurrir del tiempo, también presente en la metáfora del trapero, utilizada por Baudelaire y resaltada por Benjamin. Los traperos son el equivalente a los actuales recicladores de carretilla. "Aquí tenemos a un hombre que deberá recoger las basuras del pasado día en la gran capital. Todo lo que la gran ciudad arrojó, todo lo que perdió, todo lo que ha despreciado, todo lo que ha pisoteado, el lo registra y lo recoge"22. Así como los recicladores se detienen en las bolsas de basura buscando aquello que puede resultar útil, el poeta vaga entre la multitud buscando rimas $^{23}$. Si retomamos las nociones expuestas al hablar de Freud, el reciclador/poeta recoge todo aquello que la gran masa no ha podido procesar y que se empieza a acumular. El reciclador no rescata objetos para conservarlos tal cual: los transforma y los pone en

\footnotetext{
20 Ibid., p. 146.

${ }^{21}$ Cf. Honneth, Axel, Crítica del agravio moral. Patologías de la sociedad contemporánea, México,

D.F: Fondo de Cultura Económica, 2009, pp. 5I- 116.

22 Benjamin, op. cit., p. 98.

${ }^{23}$ Cf. ibid.
} 
circulación nuevamente. Así, el poeta transforma las experiencias inconscientes de la masa.

Baudelaire también compara al poeta con el flâneur: paseante que sin rumbo fijo deambula a paso lento por la ciudad, observando. Estos paseos llegan a hacerse imposibles en la multitud de París. En "Pérdida de aureola", el poeta ya no pasea, se abre camino por las abarrotadas calles. Al hacerlo, pierde la aureola que lo consagra como poeta y termina en una taberna. "Hace un momento, mientras cruzaba apresuradamente el boulevar, saltando entre el barro, a través de ese móvil caos donde la muerte llega al galope por todas partes a la vez, mi aureola, en uno de mis bruscos movimientos, se me deslizó de la cabeza y calló al fango de la calzada. Yo no tuve el valor de recogerla. Juzgué menos desagradable perder mis insignias que dejarme romper los huesos" 24 . Al igual que para el reciclador, hurgar entre los desperdicios de la gran ciudad no es una elección del poeta: es una condición que la masa le impone.

\section{§ 6. Un astro sin atmosfera}

La poesía de Baudelaire se presenta como "un astro sin atmosfera en el firmamento del Segundo Imperio"25. David Kelman se dedica a examinar esta metáfora ${ }^{26}$. Aunque Baudelaire se conecta con su contexto histórico de una manera muy intensa y particular (como trapero, como flâneur, como conciencia de los shocks de su época), se encuentra, al mismo tiempo, desfasado de ella. No sólo la poesía lírica, tal y como describíamos al principio, es incapaz de hacer contacto con la experiencia de los lectores. Baudelaire también representa una figura inactual e incomprendida. Su poesía se alimenta de la masa, pero en la masa no hay espacio para su poesía.

El poeta se hace consciente en y a través de la multitud: esta es el insumo del cual se alimenta y de donde nace la poesía. La multitud, sin embargo, es incapaz de escuchar al poeta: no puede cobrar conciencia de sí misma a través de la poesía; permanece alienada. El método psicoanalítico no extirpa el mal, sino

${ }^{24}$ Baudelaire, Charles, Obras, México, D.F.: Aguilar, 196I, p. 420.

25 Ibid., p. 170.

I I $0 \quad{ }^{26}$ Cf. Kelman, op. cit., pp. 123-I47. 
que auto-inmuniza al sujeto: le enseña a vivir con él. La poesía de Baudelaire no puede ser edificante ni políticamente constructiva. No es, como dijimos al comienzo, una forma de catarsis. Podría entenderse como redención, siempre y cuando entendamos esta palabra como pagar por el otro con la propia vida. 